\title{
6 The Ethnohistory of the Bathudi Tribe of Mayurbhanj in Odisha
}

Kumarmani Nayak, Research Scholar in History, North Orissa University and Reader in History, B.B. College,Baiganbadia, Mayurbhanj, Odisha.

email:bbcollegebaiganbadia@gmail.com

Keyword: Bathudi tribe, Ethnohistory, Mayurbhanj, Odisha,

The Bathudi tribe is only found in India in the state of Odisha, Jharkhand, Bihar and West Bengal. They live in the State of Odisha in the district of Mayurbhanj, Keonjhar and Balasore. They are only found in large numbers in the district of Mayurbhanj. They are largely concentrated in Panchpir subdivision. They are not less in numbers in Baripada, Kaptipada and Bamanghaty subdivision.

The origin of the Bathudi tribe is in dark due to lack of historical evidence. The name Bathudi is derived from the term 'Barthali'. 'Bar' means twelve and 'Thali' means land or place. ${ }^{2}$ The alternative names of this tribe are Bahutali, Bathuhuli, Bathdi and Bathuri. There is a tradition among the Bathudis that they originally belonged to a place called Batuligarh in Ayodhya from where they migrated following the course of Godavari river in the Deccan. From the point of the geographical position of Ayodhya, their story of migration to the Deccan is not believable. But the other part of the story which has mentioned that the Bathudis first came to the Similipal hills in course of their migration to the Mayurbhanj State. ${ }^{3}$ It is further supported that there is a village named Ayodhya in the border area of Mayurbhanj in the Nilgiri State. ${ }^{4}$ According to Satpathy (1968), the Bathudi left Ayodhya in Search of Ramachandra during the rule of King Bharat. But they could not able to find him. Instead of going back to the native place they remained at Chotanagapur plateau. Having heard about the availability of land in Jamuna-Baradanda of the Similipal hills, they migrated to that place. ${ }^{5}$

When the Bathudis came to the Mayurbhanj State, they defeated king Chandrasen of Similipal hills selected twelve valleys (Barthali) and established themselves there. In the course of time, they became the chief of Adipur, Jamuna-Baradanda, Karanjia and Jashipur. During the $6^{\text {th }}$ or $7^{\text {th }}$ Century A.D. a Bathudi King established a kingdom named as Gada Similipal and started ruling over it. The king also installed 


\section{(C) Kumarmani Nayak}

Gadachandi there and assumed the title of Mohapatra. ${ }^{6}$ In the course of time due to the growth of their population, they prepared more and more lands for cultivation. Thus they moved other parts of the state for their settlement. At last they came under the control of the Bhanja rulers of the Mayurbhanj State. The Bhanja rulers had twenty-two Zamindars, out of which four were the Bathudis who were the Zamindars of Similipal, Adipur, Daspur and Karanjia. They were all honoured with the title of Mohapatra, a flag, a silver umbrella and a Chamara which they used to display on festive occasions. But during the reign of Maharaja Jadunath Bhanj, the Bathudi chief of Bamanghaty became oppressive and revolted against the ruler. The king defeated the Bathudi chief in the battle of Tentaposi and drove him out of Bamanghaty. ${ }^{7}$

Presently the Bathudis live mostly in the plain areas among other tribes and castes in the district of Mayurbhanj. They are one of the prominent Scheduled Tribe of the district. But they still prefer to be known by the caste name Kshatriya Hindu. It is only a few years back that the Bathudis were occupied the positions of rulers, ministers and commanders. They are the real Odia fighters of ancient Kalinga or the Gajapati empire and are worthy successors of the Paik lineage which is evident from their titles, namely, Senapati, Dandasen, Biswal, Khandei, Bebarta etc. ${ }^{8}$ They believe that the Aryan blood runs in their veins and are predominately Hindu in their culture. They are considered to be the clean caste of the Hindu society and equal with the Brahmans. The Brahmanas and the Vaisnavas take food in the houses of the Bathudis on festive occasions and ceremonies. The Bathudis of Mayurbhanj feel it offensive if they are called as a tribe or Adivasi. They all make use of the Hindu temples and also act as priests. But the Bathudis consider the Similipal as their motherland. It is their holy place from where their ancestors migrated to other parts of the state.

\section{Society:}

The social life of the Bathudis presents a fascinating study for social scientists. Their social structure keeps a hierarchy of social classes or castes. There are subgroups within them. The categorization into the castes is quite similar to that of Hindus practising neighbours of the Bathudis. Like other castes and tribes, they have divided into several clans like Kargali or Kaga, Dahukcharai, Kurgotra, Khandan, Panipok, Hasti, Lalsaluk and Naga. ${ }^{9}$ They have also a number of gotras. These totemic clans are named behind sages and saints, birds, animals, local plants and other natural things. The name of their gotras are Parasara, Nageswara, Ganeswara, Kashyapa, Saila or Salo, Bharadwaja, Dhanphula, Hasti, Padhyala, Dahuka, Tanda, Panipoka, De Chadhei, Matiana, Kukur Mundia and Sasthi. ${ }^{10}$ With the growth of 
The Researchers' - Volume VI, Issue I, 10 March-2020

International Research Journal (Double-blind peer-reviewed)

Date of Acceptance : 12 November 2019
ISSN : 2455-1503

Impact Factor - 3.635

DOI - 10.21276/tr.2020.6.1.AN6

\section{(C) Kumarmani Nayak}

population, they have divided into a number of families. Some of them use the surname as Bagjadia, Biswal, Das, Dhal, Giri, Jamundia, Kuanr, Khatua, Kappadiya, Modei, Manika, Patra, Ranasiya, Rout, Suliya, Senapati etc. ${ }^{11}$ The marriage within the clan is not allowed. Each clan has again its gradations of rank, consisting of four orders, namely (1) Mohapatras, (2) Nayaks, (3) Paiks and (4) Muliyas or Labour classes. ${ }^{12}$ The Census of Mayurbhanj, 1931 mentions about 56 titles of the Bathudis of Mayurbhanj. These titles were given to them as a reward by the rulers or zamindars to their ancestors for their distinguished service. Presently they are using more than 100 surnames. Family: Family is the smallest unit of the Bathudi social structure. It is nuclear, patrilocal and patrilineal. It consists of members who are related to each other by birth and marriage. The ancestry of the family is counted through the male line from father to son. As soon as the sons get married, they establish new houses. After the death of the father, the property is always inherited by the son. It is equally distributed among all sons, but the eldest son gets Badabhag (Lion's share) than others. ${ }^{13}$ Regarding the adoption of a boy, the Bathudi have no hard and first rule. But the adoption is needed to get social recognition. He gets social recognition when the members of his society are given a good feast by the adopter. The Bathudis have also joint and extended families. The eldest male member of the family is regarded as the head of the family. The relation of the husband-wife is very cordial. The co-operation between the husband and the wife helps to maintain a happy family life. The children also co-operate the parents in the performance of the work in the house or in the field. The Bathudis not only maintain the good relation with their lineage and clan groups but also keep relation with other tribes and castes where they live together. Kinship: The Bathudi kinship system is based on the concept of marriage and parentage. The family, lineage and clan are the groups of kin-based on the concept of the blood relation. The marriages between blood relatives are strictly prohibited in the Bathudi community. Marriage establishes a kinship bond between bride and groom and their kin. It also establishes a relationship between several families related to the bride and the groom. Housing and Interiors: The Bathudis are very rigid in the affairs, though they live together with other tribes and castes in the same villages. But they maintain their own identity. In multi-ethnic villages, they live in separate hamlets called Bathudisahi. The organization of the village is along a single road with houses built in two rows along with it. The houses are less distance to the road. One has to cross the fence made with bamboo and wood in entering into the house. The doors of the houses are not to the road. Generally, there is a courtyard for each family. For the entrance of light and wind, small round holes have made on the head of the wall. Most of the Bathudis have houses made of mud walls and thatched roofs. 


\section{(C) Kumarmani Nayak}

The well-to-do have separate rooms for storage, cooking and animals etc. The kitchen is considered sacred and it is called Ishan Ghar. They have Agnimata (Goddess of fire) on the front of their houses to save the house from the wrath of fire. They like to decorate their walls with multi-coloured floral designs. Their walls look like cement paint. The Bathudis cook food in earthen vessels and use utensils for consuming food. In terms of furniture, they make mats and charpoys and the rich Bathudi uses wooden furniture. Now they are making their houses permanent and are using the utensils of brass, bronze and aluminium. But in rural areas, the old habit is still preserved. Some of them have made, tiled or pucca houses their village getting financial assistance from the government. Food and Drink: The Bathudis of Mayurbhanj are very simple in their food habit. The diet is both balanced and enriching which includes both vegetarian and non-vegetarian. Rice is the staple food which is eaten throughout the year. Milk and milk products are the favourite food of the Bathudi. They take non-vegetarian food in religious ceremonies. They eat mutton and fowl. The poor like to take the watered rice and fried rice. The drinking water used to take from rivers, streams and ponds. Now they are using the water of the wells and tube wells to avoid the diseases caused by the impure water. They prefer to take clean food and some of them also take Handia, Kalei and Kurkuti (termites and red ants). ${ }^{14}$ In the past, they kept off taking alcohol. He who took alcohol, created disturbances, he was ostracized and disallowed to enter into the public places. But presently they used it without any hesitation. Dress and ornaments: In the past, the Bathudi had not separate dress like the Santhals. After 1980, when they went to the Athara Deula to worship their tutelar deity, Badam, they wore dhoti, ganji, gamchha and sari. Since it was attached to their clothing style. Generally, the dress of the Bathudis is similar to the tribal dress of their surroundings. In early days both men and women were fond of wearing ornaments made of brass, silver, seeds and thread. They also wear sacred thread like the Brahmins and the Kshatriyas. But in recent time, the use of traditional ornament is rarely found among the Bathudis. With the growing contact of the outside world, the clothing style of the Bathudis is getting more and more changed. Tattooing is very much popular among the Bathudi women. It is called Khada. Before marriage, a girl makes one or two floral designs (tattoos) on her forehead or arm as per their traditions.

\section{Youth Organization:}

In each Bathudi village, there is a youth organization called Bhendapia or Dhanguli Basa or Akhada Ghar. It is symbolized the unity of the village. This dormitory also serves as a court where the village elders are 


\section{(C) Kumarmani Nayak}

assembled in morning and evening to decide the cases and take important decision of the village. The rehearsal of the Changu Dance is also held there. The dormitory provides the art of co-operation, fellow feeling and hospitality to the boys and the girls of the village. They are taught to develop among them, the sense of responsibility to preserve the values of their society and culture. The youth organization which made the Bathudi society glamorous has lost its early glory. It is due to the indifferent attitude of the youth. Birth and Death Rites: The Bathudis consider the birth of a boy or a girl as valuable in their society and do not make any discrimination in caring and rearing. During the pollution period, they observe certain taboos and do not perform any sacred activity. Among the Hinduised tribes, namely, Gond, Savar, Deshia Khond, Bhuyan, Bhumij, Bathudi etc. simulation of the Brahminical concepts of purity and pollution are found to a considerable extent. ${ }^{15}$ When a child is born, the rituals and ceremonies are generally held on a ninth day. It is called Nalita or Nabeda. Delivery is carried out inside the house. An old experienced woman of their community called Kusuruni Budhi takes an active part for the smooth delivery. ${ }^{16}$ From the time of birth to the purification day, the child remained in the Antudisala or a room where the baby is born. The name-giving ceremony is called Ekuisa. It is observed on the 21 st day of the newborn baby. On this day the family preceptor and Vaishnavas are feasted. The horoscope of the child is prepared. When a person dies, the Bathudis make necessary arrangement for disposal of the dead body. The mourning period lasts for ten days. They believe that unnatural death is an indication of misfortune for the tribe and caused by the evil spirits. When the aged is placed on the funeral pyre, he or she has covered a new piece of cloth, a Tulsi plant is tied around his or her neck. They donate gold or cow in the name of dead person. ${ }^{17}$ The eldest son and in his absence, the chief of the deceased set fire to the pyre. On the 11th day, the shradha ceremony is conducted by a Brahmin. It is the ceremony where the Bathudis offer food to the dead. On this day, Brahmans and Vaishnavas take food in the house of the performer. A feast is also provided to the entire members of their community to become pure.

\section{Marriage:}

The Bathudis of Mayurbhanj generally prefer to the marriage by negotiation called Panteka. ${ }^{18}$ There are seven kinds of marriage within the Bathudi community of Mayurbhanj. These are (1) Dekhasuna Baha (Marriage by negotiation), (2) Sangha Baha (marriage after divorce), (3) Ghinpala Baha (Love marriage or marriage by mutual consent), (4) Ghardhuka Baha (Marriage by intrusion), (5) Badi Baha (marriage by betting), (6) Kamkara Baha (marriage by service) and (7) Gharjamai (marriage by adoption). The 


\section{(C) Kumarmani Nayak}

marriage proposal is always received from the bride-groom's side. Marriage is performed according to the vedic rite. They engage Brahmins to officiate as priests on the occasions of marriage. Formerly, such services used to be given by Madhei and Pathuria section of the Bathudi community who have not lost all holds on their right. In case of divorce, the parents of the divorce seek permission for Mukti from the council of village elders presided over by the Pradhan.

\section{Polity:}

Every tribal community has its own political structures to govern and regulate its members. The Bathudis have their traditional political organizations that govern and regulate their socio-cultural life and bring peace and solidarity in their community. The tribal political systems were influenced by the revenue administrative organization of the concerned state. The political systems of Santals, Munda, Ho, Bhumij, Bathudi living in Mayurbhanj State were all influenced by the revenue territorial structure of the concerned state. 19 The hierarchical rank of political systems of the Bathudi tribe from the bottom to the top are (1) family, (2) lineage, (3) village, (4) paragana and (5) the king, the head of the state. The jurisdictions, powers, and functions of each political organization have clearly defined. The roles of the functionaries are important, but those of the lineage and the village heads are most important in keeping up the social order. These functionaries are the guardians and custodians of tribal norms, customs and customary laws. The nature of the cases dealt mostly by the caste council. The violations of social norms are strictly viewed. When a person is ousted from his community, nobody in his community keeps a relation with him as well as his family. The traditional organizations become weak after the introduction of the Panchayat Raj system; yet these are important socio-cultural institutions to regulate the sociocultural life of the tribals. Where the Bathudis are numerically strong in Mayurbhanj, their caste council, as well as village council is in their hands. They control the political, social, economic and cultural life of their people and maintain all the customary laws. Where they are less in numbers, the political, social and economic control is out of their hand.

\section{Economy:}

The Bathudis work from morning to night for their livelihood. When they were in the Similipal hills, they cultivated small patches of lands and engaged in fishing, hunting and collection of forest produce to supplement their basic needs. Now they are the settled agriculturalists and often supplement their economy with hunting and gathering. After leaving the bed, the male members of the Bathudi feed straw 


\section{(C) Kumarmani Nayak}

to the cattle and prepare themselves for the work in the field. The woman folks start household activities. Males go to the fields early in the morning. Their wives and children assist them in the field. In the field, women help men in sowing, weeding, transplanting, watching, harvesting and storing. When they come to the home, they collect and bring firewood, leaves, greens, mushrooms and tooth twigs for domestic use. When there is no work, man and woman go to the forest to gather edible roots, tubers, fruits and flowers like Mahua and salai. ${ }^{20}$ Hunting and gathering forest produce are no longer practised due to restriction imposed on the forests. Some do fishing in local ponds and local streams. In remote areas husking paddy is prevalent. The cultivable lands of Mayurbhanj are five categories namely, (1) Dahi, the worst kind of upland, (2) Asu, the upland (3) Kala, the homestead land, (4) Pal, the alluvial land on the banks of rivers and (5) Jal, the paddy land. ${ }^{21}$ The Bathudis like to use traditional implements in agriculture. The modern agricultural implements are supplied to help the farmers. But the Bathudis do not take much interest on agriculture. They hesitate to cultivate and gradually become idle in their village. They do not keep their lands under their possession due to the non-payment of land revenue. The local zamindars possessed and sold them as a result of which most of them become landless. Thus most of the Bathudis in Mayurbhanj are poor having a few patches of land. They invariably incur loans on a mortgage of household brass utensils, gold and silver ornaments. They work as casual labour. But they do not like to spend money on agriculture. All agricultural process is carried out by the family members. The Bathudis who were in high ranks are now trembling on the verge of poverty and ruin, falling in debt. They look no better than the Kols, the Santals, and other aboriginal tribes. ${ }^{22}$ The Central and State government have started several schemes to develop the economic, political, housing, educational and health conditions of the Bathudis. In order to increase the economic status, subsidy and loans have been provided by the Nationalised banks and cooperative societies. But most of the Bathudi tend to be in debt with the local Mahajans. In reality, they are far away from the benefits of development as most of them are illiterate. They do not avail the benefit of reservation on jobs. Their benefits are availed by other tribes in Mayurbhanj who are numerically dominated and educationally well learned. Religion: The religion of the Bathudis is an admixture of animism, nature worship, supernaturalism and ancestor worship. Their beliefs and practices aim at personal security and happiness as well as group solidarity and community well-being. Hinduism is the predominant religion followed by the Bathudi of Mayurbhanj. Their beliefs, customs and traditions are quite similar to the Hindus. They worship the hills, forests and stone. Tree worship is also popular among them. They worship gods and goddesses in the shape of blocks of stone. Badam is the presiding 


\section{(C) Kumarmani Nayak}

deity of their tribe. They consider Badam as lord Balaram, the creator of the universe. He is formless. Athara Deula is the abode of Lord Badam. The temple is located at Lembugada near Bakua in the core area of Similipal Tiger Reserve under Jashipur Block of Mayurbhanj district. According to the Bathudis, this temple has not been built by man; it has been built by God. But it is a most ancient temple of Odisha. It has been built by the laterite stone without cement and lime. Athara Deula consists of 18 temples inside and around the Similipal hills. These are natural caves. The only temple, Manab Deula has been built by man, for which it is named as Manab Deula. The Bathudis consider this place like Macca and Madina of Muslims or Gurudwara of Sikhs. ${ }^{23}$ Without visiting Athara Deula once, life is meaningless for the Bathudi. When the Maghuni Puja is over, no restriction is imposed in entering into the jungle, the head priest of Lord Badam known as Devaraja or Thakuraraja or the Maharaja sends a message on the 10th day of Chaitra to visit Athara Deula. As per his instruction, the meeting of the village council is held. The lists of devotees both male and female are prepared. ${ }^{24}$ The devotees are not allowed to worship lord Badam wearing modern dresses. Male wears white cloth, white Ganji and gamchha. Female wears white sari with a red border. Only fruits, molasses, ganja, resin, camphor, honey and milk are offered to Lord Badam as an oblation. ${ }^{25}$ Now, the temple is on the verge of destruction. This temple needs to be preserved to recall the history and culture of the Bathudis of Mayurbhanj. Thus the Bathudis are one of the ancient tribe of North Odisha. Most probably they have migrated to the hilly tracts of this land in a remote past. They started to live as an isolated community with their own cultural identity. In the course of time, they adopted the culture of Hindus which has been revealed in their social life. Though they have appeared as an agrarian tribe, they could not able to improve in the field of cultivation as a result of which most of them are below the poverty line. Presently the popular Govt. taking care for the development of the tribes by which the food problem has been solved to some extends. Housing, education and employment facilities should be given to them for their all-round development. Otherwise, the poor Bathudis will be far from the mainstream.

\section{Reference}

1. Odisha District Gazetteers Mayurbhanj, Gopabandhu Academy of Administration (Gazetteers Unit), General Administration Department, Government of Odisha, 2016, p.105.

2. Santanu Kumar Acharya, Karanjia Diary, Cuttack, 1984, p.73. 
The Researchers' - Volume VI, Issue I, 10 March-2020

International Research Journal (Double-blind peer-reviewed)

Date of Acceptance : 12 November 2019
ISSN : 2455-1503

Impact Factor - 3.635

DOI - 10.21276/tr.2020.6.1.AN6

(C) Kumarmani Nayak

3. Mohammad Laeequddin, Census of Mayurbhanj State, 1931, Vol-I- Report, Culcutta, 1937, p.200.

4. Ibid; p.162

5. Swaran Singh, Bathudi and Sourti Tribes, New Delhi, 1994, p.10.

6. Sharat Chandra Nayak, Mayurbhanj Sanskrutire Bathudi Janajati, Baripada, 2013, p.60-61.

7. Shyam Sundar Sarangi, Mayurbhanj Itihas, Baripada, 2005, p.36.

8. Santanu Kumar Acharya, op.cit; p.238.

9. Swaran Singh, op.cit; p.36

10. The data has been collected from Rajkishore Nayak and Nabakishore Biswal of Bhugudakata, W.No.-21, under Baripada block on 14.07.17.

11. Nagendranath Vasu, The Archaeological Survey of Mayurbhanj, Vol-I, Calcutta, 1912, p.128.

12. Ibid.

13. Vide Pashupati Prasad Mahato's article, Customary Law of the Bathudi of Orissa, Published in Tribal Ethnography, Customary Law and Change, (ed) by Kumar Suresh Singh, New Delhi, 1993, pp.117-126.

14. Swaran Singh, op.cit; p.11

15. Vide K.K. Behera and K.K. Mishra's article, Religious Rites and Festivals of the Tribes of Orissa, published Tribes of Orissa, (ed) by B.C. Roy, New Delhi, 2010, p.41.

16. This fact is collected from Kabita Nayak of Bhugudakata, W.No.-27, Baripada on 20.05.2018.

17. Nagendranath Vasu, op.cit; p.131.

18. Sharat Chandra Nayak, Mayurbhanj Sanskrutire Bathudi Janajati, Baripada, 2013, p.64.

19. N.K. Behera, Tribal Societies of Orissa, in Tribes of Orissa ST and SC Development Department, Government of Orissa, 2004, p.40.

20. V.S. Upadyay and Gaya Pandey, Tribal Development in India, A critical Appraisal, Ranchi, 2003, pp.102-105.

21. J.N.S.D. Sachan, Changing Socio-Economic and Cultural Profile of the Lodhas of Mayurbhanj (unpublished D.Litt thesis) North Orissa University, Baripada, 2014, pp.182-183.

22. Nagendranath Vasu, op.cit., p-132.

23. Bimbadhar Behera and Lagnajeet Pradeep Rout, Bathudi Janajati Jeevan Dhara O Sanskruti, Puri, 2017, p.58. 
The Researchers' - Volume VI, Issue I, 10 March-2020

International Research Journal (Double-blind peer-reviewed)

Date of Acceptance : 12 November 2019
ISSN : 2455-1503

Impact Factor - 3.635

DOI - 10.21276/tr.2020.6.1.AN6

\section{(C) Kumarmani Nayak}

24. Ibid., p.74.

25. Vide Sabyasachi Das's article, Bathudi Adivasi Sanskrutira Badam Thakura Balaram, Published in the Utkal Prasanga, Vol-69 (ed) by Hussain Rabi Gandhi on behalf of Information and Public Relation Department, Odisha, July 2013, pp.182-184. 